\title{
Relationship between the sectional area of the rectus capitis posterior minor and the to be named ligament from 3D MR imaging
}

Mei-Yu Sun ${ }^{1}$, Xu Han ${ }^{1}$, Meng-Yao Wang ${ }^{1}$, Dian-Xiu Ning ${ }^{1}$, Bin Xu', Li-Zhi Xie ${ }^{2}$, Sheng-Bo Yu ${ }^{3}$ and Hong-Jin Sui ${ }^{3^{*}}$ (D)

\begin{abstract}
Background: To evaluate the maximal sectional area (SA) of the rectus capitis posterior minor (RCPmi) muscle and its potential correlation with to be named ligament (TBNL) in the suboccipital area using 3D MR imaging.

Methods: A total of 365 subjects underwent sagittal 3D T 2 WI MR imaging of the RCPmi and TBNL. Among them, 45 subjects were excluded due to a particular clinical history or poor image quality. Finally, 320 subjects met the inclusion criteria, including 138 men and 182 women. The 624 RCPmi muscles were classified into positive and negative groups according to their attachment to the TBNL. Two experienced radiologists manually measured the maximum SA of the RCPmi muscle on the parasagittal image with a $30^{\circ}$ deviation from the median sagittal plane. The correlations between the SA and the subject's age, height, BMI, gender, handedness, and age-related disc degeneration were tested by Spearman analysis. The SA differences between different groups were compared using independent samples t-test.

Results: A total of 123 RCPmi-TBNL attachments were identified in the positive group, while 501 RCPmi muscles were identified in the negative group. The SA of the $624 \mathrm{RCPmi}$ muscles was $62.71 \pm 28.72 \mathrm{~mm}^{2}$ and was poorly correlated with the subject's age, BMI, or handedness, with no correlation with age-related disc degeneration. A fair correlation was found between the SA and the body height in the whole group, and poor correlation in each male/female group. The SA of the RCPmi muscle in males was significantly bigger than that in women ([75.54 \pm 29.17] vs. [52.74 \pm 24.07$] \mathrm{mm}^{2}$ ). The SA of RCPmi muscle in the positive group was significantly smaller than that in the negative group ([55.95 \pm 26.76$] \mathrm{mm}^{2}$ vs. [64.37 \pm 28.97$] \mathrm{mm}^{2}$ ).

Conclusions: Our results revealed a significantly smaller SA of the RCPmi in subjects with RCPmi-TBNL attachment. Besides, a larger SA of the RCPmi was correlated with the male gender. These findings suggest that the SA of the RCPmi ought to be interpreted with care for each patient since there could be considerable variations.
\end{abstract}

Keywords: Myodural bridge, To be named ligament, Magnetic resonance imaging, Rectus capitis posterior minor, Sectional area

\footnotetext{
* Correspondence: suihj2017@126.com

${ }^{3}$ Department of Anatomy, College of Basic Medicine, Dalian Medical

University, Dalian 116044, People's Republic of China

Full list of author information is available at the end of the article
}

(c) The Author(s). 2020 Open Access This article is distributed under the terms of the Creative Commons Attribution 4.0 International License (http://creativecommons.org/licenses/by/4.0/), which permits unrestricted use, distribution, and reproduction in any medium, provided you give appropriate credit to the original author(s) and the source, provide a link to the Creative Commons license, and indicate if changes were made. The Creative Commons Public Domain Dedication waiver (http://creativecommons.org/publicdomain/zero/1.0/) applies to the data made available in this article, unless otherwise stated. 


\section{Background}

The myodural bridge (MDB) is a connective tissue band that connects the suboccipital muscles and nuchal ligament (NL) with the cervical spinal dura mater (SDM) [1-6]. It has been recently confirmed as a conserved structure in mammals [7-9]. The MDB has a critical role in transmitting tensile force from its muscular and ligamentous components to the SDM, which has an essential role in the etiology of headache and cervicocephalic pain syndrome [10-14]. The rectus capitis posterior minor (RCPmi) was the first suboccipital muscle identified to attach to the dorsal cervical SDM at the posterior atlanto-occipital (PAO) interval [1]. The architecture of muscle, particularly the cross-sectional area (CSA), is a predictor of its force generation [15]. Previous research has focused on the CSA or relative CSA of the RCPmi muscle as biomechanical contributors to cervicocephalic pain syndrome, mild traumatic brain injury (mTBI), and headache syndromes [10-13, 16]. Several studies have shown that the CSA of adult RCPmi muscles is negatively correlated with the severity of chronic headaches [10-13, 16]. Fernfindez-de-lasPenas et al $[10,11]$ have shown that reduced axial CSA of the RCPmi is correlated with symptom severity in patients with chronic tension-type headache $(\mathrm{CTTH})$ and mTBI. Yet, in contrast to these studies, Yuan et al have reported increased sectional area (SA) of RCPmi muscle in patients with chronic headaches [13]. To correctly assess the effect of the RCPmi muscle' SA on symptom severity in patients with headache syndrome, it is necessary to thoroughly clarify the magnitude of the variations in the SA of the RCPmi muscles in asymptomatic controls. So far, this issue has not yet been comprehensively addressed. Consequently, an assessment of the SA of the RCPmi muscle in asymptomatic controls is essential for an accurate evaluation of the effect of the SA of the RCPmi muscle in symptomatic patients.

Magnetic resonance imaging (MRI) is a powerful noninvasive imaging tool used to detect the SA of the RCPmi muscle. Though two-dimensional (2D) axial MR images are considered optimal for evaluating the SA of the RCPmi muscle, experimental variables, such as selected image level and variable neck posture, can lead to significant error $[17,18]$. Because the reduction in slice thickness lessens partial volume effects that may induce inaccuracy of SA measurement, three-dimensional (3D) MRI may facilitate accurate SA measurement of the RCPmi due to its thinner slices and isotropic postprocessed reconstruction. In the present study, physiologic CSA was not calculated though it is more commonly used in conventional calculations to determine muscle atrophy or hypertrophy [12, 16-18]. A narrow pointed tendon attaches the RCPmi to the tubercle on the posterior arch of the atlas. As it ascends, it broadens before attaching to the medial part of the inferior nuchal line and the occipital bone between the inferior nuchal line and the foramen magnum. The physiological CSA of each fan-shaped RCPmi cannot be accurately calculated due to underlying difficulties in taking the identical measurement plane, which could be influenced by factors such as, selected scanning level, atlanto-occipital interspace distance, and neck posture [17, 18]. Referring to the method described by Yuan et al, the angle between the medial and lateral borders of the RCPmi was measured, and the value was $(60.7 \pm 4.4)^{\circ}$. Hence, $60^{\circ}$ from the midline represented the mean of the orientation in the different subjects. Thirty degrees with the largest RCPmi muscle were set as the optimal angle for a better view of the muscle [13]. Therefore, we measured the maximal SA of the RCPmi muscles on the parasagittal image with a $30^{\circ}$ deviation from the median sagittal plane through the mid-posterior arch of atlas and the occipital bone. Nevertheless, to the best of our knowledge, no studies are reporting the maximum SA in the RCPmi muscles using 3D MRI, which could be used to determine the variance in SA of the RCPmi muscle for related pathologic studies.

Multiple studies have confirmed the binding of the NL attachment to the cervical SDM via the PAO and posterior atlantoaxial (PAA) intervals [3, 5, 19]. In 2014, Zheng's study confirmed that the local enhancement of the NL emanated from the posterior border of NL projecting forward and upward to the cervical dura mater, which she termed as the to be named ligament (TBNL) [20]. The TBNL may participate in cervicogenic pain syndrome by bridging the dorsal extensor musculature of the cervical spine to the pain-sensitive dura mater. In 2017, Yuan et al found that $11.43 \%$ of the RCPmi muscles gave off muscular bundles that merged and terminated at the TBNL whose morphology was influenced by this additional connection [21]. Yet, whether this physical connection from the RCPmi to the TBNL affects the maximum SA of the RCPmi muscle remains unclear.

The SA of RCPmi muscle has been suggested as a potential contributor to headache and cervicogenic pain symptoms; hence, the first aim of this study was to determine the anatomical SA of the RCPmi muscle using $3 \mathrm{D} \mathrm{T}_{2}$-weighted $\mathrm{MR}$ imaging. The RCPmi and TBNL are both critical components of MDB, and their anatomic connection indicates the possibility of a correlation between them. The second aim was to investigate the relationship between the maximum SA of the RCPmi muscles with the RCPmi-TBNL attachment. We hypothesized that the RCPmi and TBNL worked together as an MDB complex to fulfill their crucial function; therefore, the maximum SA of the RCPmi muscle is negatively correlated with the RCPmi-TBNL connection. 


\section{Methods}

\section{Study population}

Institutional review board approval was obtained, and written informed consent was waived due to the retrospective nature of the study. A random 365 subjects with routine findings (including normal cervical spine and age-related intervertebral disc degeneration) were enrolled from an ambulatory outpatient population in northern China between September 2015 and December 2017. Forty-two subjects were excluded due to history of headache $(n=13)$, history of head/neck trauma $(n=17)$, diabetes mellitus $(n=9)$, surgery of head and neck $(\mathrm{n}=$ $1)$ and gross pathology $(n=2)$. Another three subjects were excluded due to poor image quality. The flow chart demonstrates the subjects' exclusion criteria (Fig. 1). Height and body weight were also measured; the body mass index (BMI) was calculated as weight in kilograms $(\mathrm{kg})$ divided by the square of height $(\mathrm{m})$. In addition, the handedness of all participants was recorded.

Three hundred and twenty subjects (mean age 43.40 years, mean height $167.21 \mathrm{~cm}, 297$ right-handed and 23 left-handed) were enrolled, including 138 men (mean age 43.36 years, mean height $174.09 \mathrm{~cm}$ ) and 182 women (mean age 43.43 years, mean height $161.99 \mathrm{~cm}$ ). The mean BMI was $23.95 \mathrm{Kg} / \mathrm{m}^{2}$ (Table 1 ).

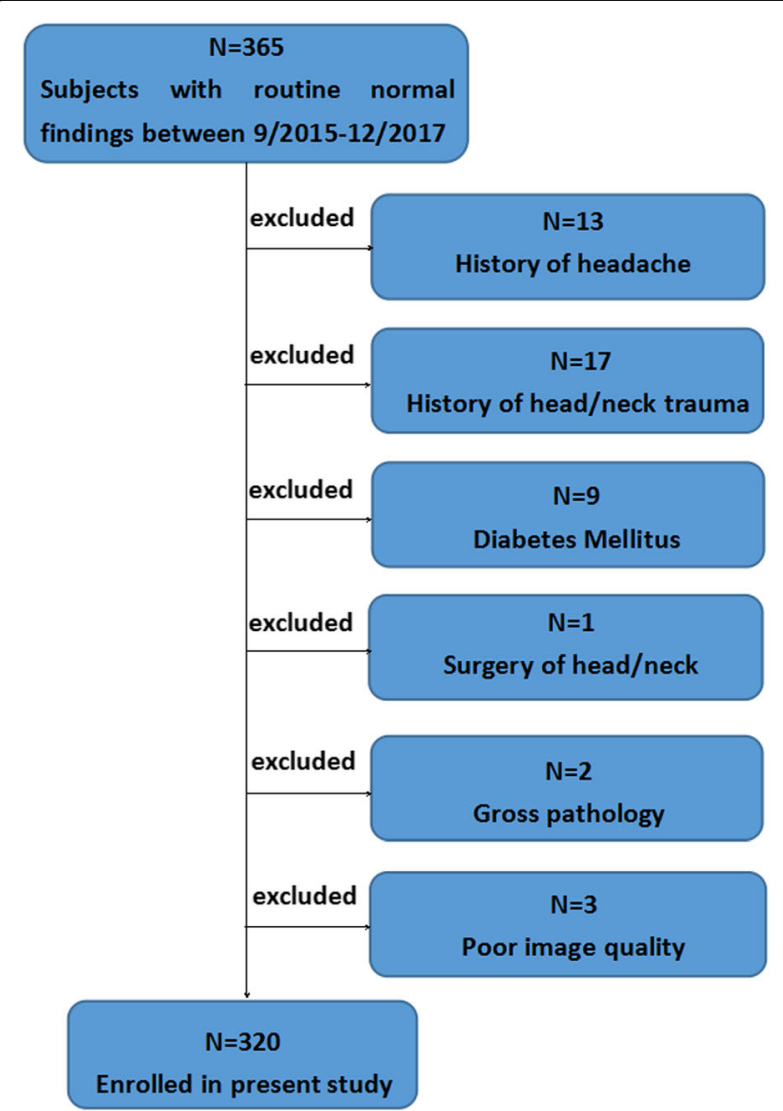

Fig. 1 Flow chart demonstrating subjects exclusion criteria

\section{MR imaging}

A $3.0 \mathrm{~T} / 1.5 \mathrm{~T}$ General Electric (GE) Magnetic Resonance Scanner (Signa, HDxt, GE healthcare, USA) was used to scan the RCPmi muscle and the TBNL of each subject in the study. Subjects were scanned in the supine position in the magnet utilizing a dedicated spinal phased-array coil that covered the whole neck and suboccipital region. The sagittal 3D $\mathrm{T}_{2-}$ weighted $\mathrm{MR}$ imaging was performed with the following parameters: TR: $2500 \mathrm{~ms}$, TE: $70 \mathrm{~ms}$, slice thickness: $1.2 / 0.6 \mathrm{~mm}$ overlap, flip angle: $90^{\circ}$, matrix: $256 \times 256$, FOV: $24 \times 24 \mathrm{~cm}$. The total imaging time was approximately $8 \mathrm{~min}$.

\section{MR imaging analysis}

The 3D $\mathrm{T}_{2}$-weighted $\mathrm{MR}$ images were interpreted by two radiologists with 12 and 10 years of experience in musculoskeletal imaging. The parasagittal or oblique sagittal images were generated by image reconstruction to determine whether there was an attachment from the RCPmi to the TBNL (RCPmi-TBNL attachment) or not. The RCPmi-TBNL attachments were identified as visible continuous hypointense strips/bands originating from the posteroinferior aspect of the RCPmi muscle and traveling inferomedially to the TBNL through the hyperintense fat in the suboccipital region. If the RCPmiTBNL attachment was observed, the RCPmi muscle was placed in the positive group; if no RCPmi-TBNL attachment was identified, it was placed in the negative group (Fig. 2). To minimize bias, the two radiologists discussed

Table 1 Descriptive characteristics and correlation with SA of RCPmi $(n=320)$

\begin{tabular}{|c|c|c|c|}
\hline General characteristics & Result & $r$ & $P$ \\
\hline Age $($ year)* & $43.40 \pm 15.45$ & -0.105 & 0.009 \\
\hline Height $(\mathrm{cm})^{*}$ & $167.21 \pm 8.48$ & 0.429 & $<0.001$ \\
\hline Male & $174.09 \pm 6.22$ & 0.216 & $<0.001$ \\
\hline Female & $161.99 \pm 5.82$ & 0.239 & $<0.001$ \\
\hline BMI $\left(\mathrm{Kg} / \mathrm{m}^{2}\right)^{*}$ & $23.95 \pm 3.65$ & 0.161 & $<0.001$ \\
\hline Gender ${ }^{\#}$ & & 0.391 & $<0.001$ \\
\hline Male & $138,(43.13)$ & & \\
\hline Female & $182,(56.87)$ & & \\
\hline Handedness ${ }^{\#}$ & & 0.132 & 0.001 \\
\hline Right-handed & 297, (92.81) & & \\
\hline Left-handed & $23,(7.19)$ & & \\
\hline Age-related disc degeneration ${ }^{\#}$ & & 0.005 & 0.908 \\
\hline None & $268,(83.75)$ & & \\
\hline Yes & $52,(16.25)$ & & \\
\hline
\end{tabular}

SA Sectional area, $B M I$ Body mass index

* Data are mean. standard deviation, \# Data are number (percentage) 


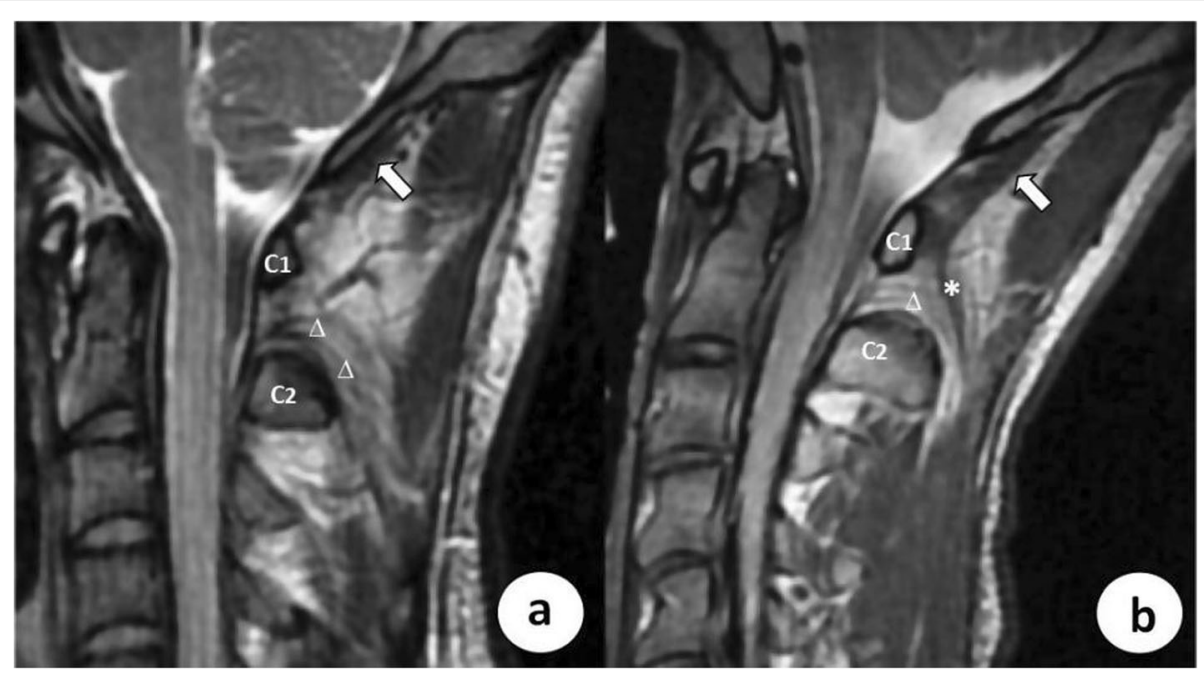

Fig. 2 RCPmi muscles with and without an attachment of the RCPmi to the TBNL. a Oblique parasagittal $T_{2}$-weighted MR image from a RCPmi in the negative group, which demonstrates no visible attachment from the RCPmi (white arrow) to the TBNL (white $\Delta$ ). $\mathbf{b}$ Oblique parasagittal $T_{2}$ weighted MR image from a RCPmi in the positive group which shows continuous hypointense strips/bands (white *) emitting from the RCPmi (white arrow) and traveling inferomedially to the TBNL (white $\triangle$ ). Note: C1: atlas; C2: axis

and agreed on standard classification criteria, and the final decision was based on consensus.

Measurements of the maximum SA of the left and right RCPmi muscles were performed by two radiologists with 5 and 4 years of experience in musculoskeletal imaging using Functool software installed on an Advantage Workstation 4.4 (Sun Microsystems, Santa Clara, Calif, USA). These two radiologists were blinded to the name and details of the patients whose images they were analyzing. Besides, the interobserver agreement was systematically assessed. The maximum SA of the RCPmi muscle was measured on the parasagittal image located between the mid-posterior arch of the atlas and the occipital bone with a $30^{\circ}$ deviation from the median sagittal plane [13]. Anatomic maximum SA was calculated inside the boundary manually placed around the perimeter of the RCPmi muscle belly (Fig. 3).

\section{Statistical methods}

All statistical analyses were performed using the SPSS 22.0 software (SPSS Inc., Chicago, IL, USA). Data were reported as mean $\pm \mathrm{SD}$. The interobserver agreement of the SA measurement was evaluated using the repeated measures ANOVA and intraclass correlation coefficient

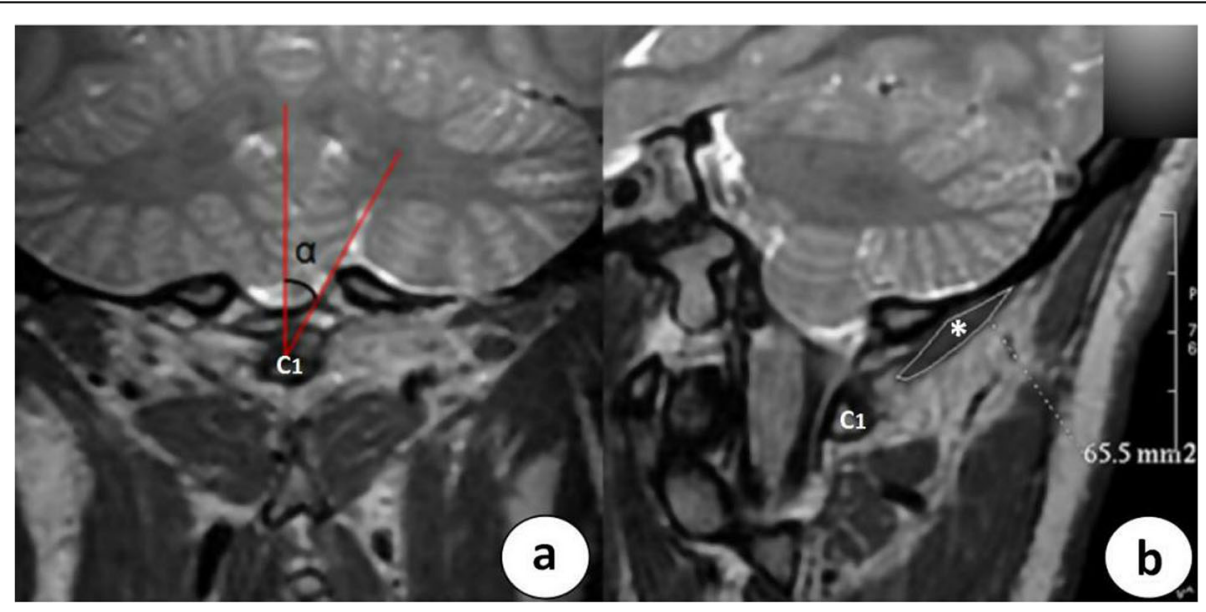

Fig. 3 The measurement method for the maximum SA of the RCPmi muscle. a Coronal $T_{2}$-weighted MR image across the posterior arch of the atlas. The SA of the RCPmi muscle is measured on an oblique parasagittal slice with a $30^{\circ}$ deviation from the mid-posterior arch of the atlas. $\mathbf{b}$ On the oblique sagittal $T_{2}$-weighted MR image defined in a., the SA of the left RCPmi muscle is given by the delineated area (white*) and has a calculated value of $65.5 \mathrm{~mm}^{2}$. Note: $\mathrm{SA}$, sectional area; $\mathrm{C1}$ : atlas; $\mathrm{a}=30^{\circ}$ 
(ICC). An ICC value $<0.5$, between 0.5 and 0.75 , between 0.75 and 0.9 , and $>0.90$ were indicative of poor, moderate, good, and excellent reliability, respectively [22]. The correlations between the SA and the subject's age, height, BMI, gender, handedness and disc degeneration were tested by Spearman analysis. A Spearman correlation coefficient $(r)$ less than 0.1 , between 0.1 and 0.3 , between 0.3 and 0.6 was considered negligible, poor and fair correlation, respectively [23]. The gender differences in the positive and negative groups were tested with a chi-squared test. The height differences between male/female and positive/negative groups were compared using an independent samples $t$-test. The SA differences, between the positive and negative groups, male versus female groups, and left versus right sides, were compared using independent samples $t$-test. For all statistical results, a $p$-value $<0.05$ was considered statistically significant.

\section{Results}

The descriptive characteristics of 320 subjects are listed in Table 1 . The body height in the male group was significantly bigger than that in the female group $(t=17.89$, $p<0.001)$. Six hundred and twenty-four RCPmi muscles were observed in 320 subjects. The RCPmi-TBNL attachment was identified in 123 RCPmi muscles with a left side to right side ratio of 61:62 and a male to female ratio of 50:73. Moreover, five hundred and one RCPmi muscles were placed into the negative group with a left to right side ratio of 250:251 and male to female ratio of
223:278. There was no statistically significant difference in gender between these two groups $\left(\chi^{2}=0.598, p=\right.$ 0.439). There was no statistically significant difference in body height between negative and positive groups $[(167.45 \pm 8.41) \mathrm{cm}$ vs. $(167.09 \pm 8.50) \mathrm{cm}, t=0.418$, $p=0.676]$.

The ICC of inter-observer agreement of the MRI measurements for the SA of the RCPmi muscles was 0.891 (95\%confidence interval 0.886-0.916), which suggested a good reliability. The mean SA was calculated for subsequent analysis. The mean SA of the 624 RCPmi muscles was $62.71 \pm 28.72 \mathrm{~mm}^{2}$ and was poorly correlated with the subject's age, BMI, or handedness, with no correlation with age-related disc degeneration (Fig. 4). Yet, SA and gender were fairly correlated. A fair correlation was also found between the SA and the body height in the whole group, and poor correlation in each male/female group (Table 1). The mean SA of the RCPmi muscles in men was significantly larger than in women. There was no statistically significant difference between the left and right RCPmi muscles. The mean SA of the RCPmi muscles in the positive group was significantly smaller compared to the negative group (Table 2, Fig. 5).

\section{Discussion}

In this study, we determined the mean and variance of the anatomic maximum SA data of the RCPmi muscles in asymptomatic subjects. Furthermore, the obtained results based on non-invasive measurements of SA on 3D $\mathrm{T}_{2}$-weighted MR imaging, suggested that a smaller SA of

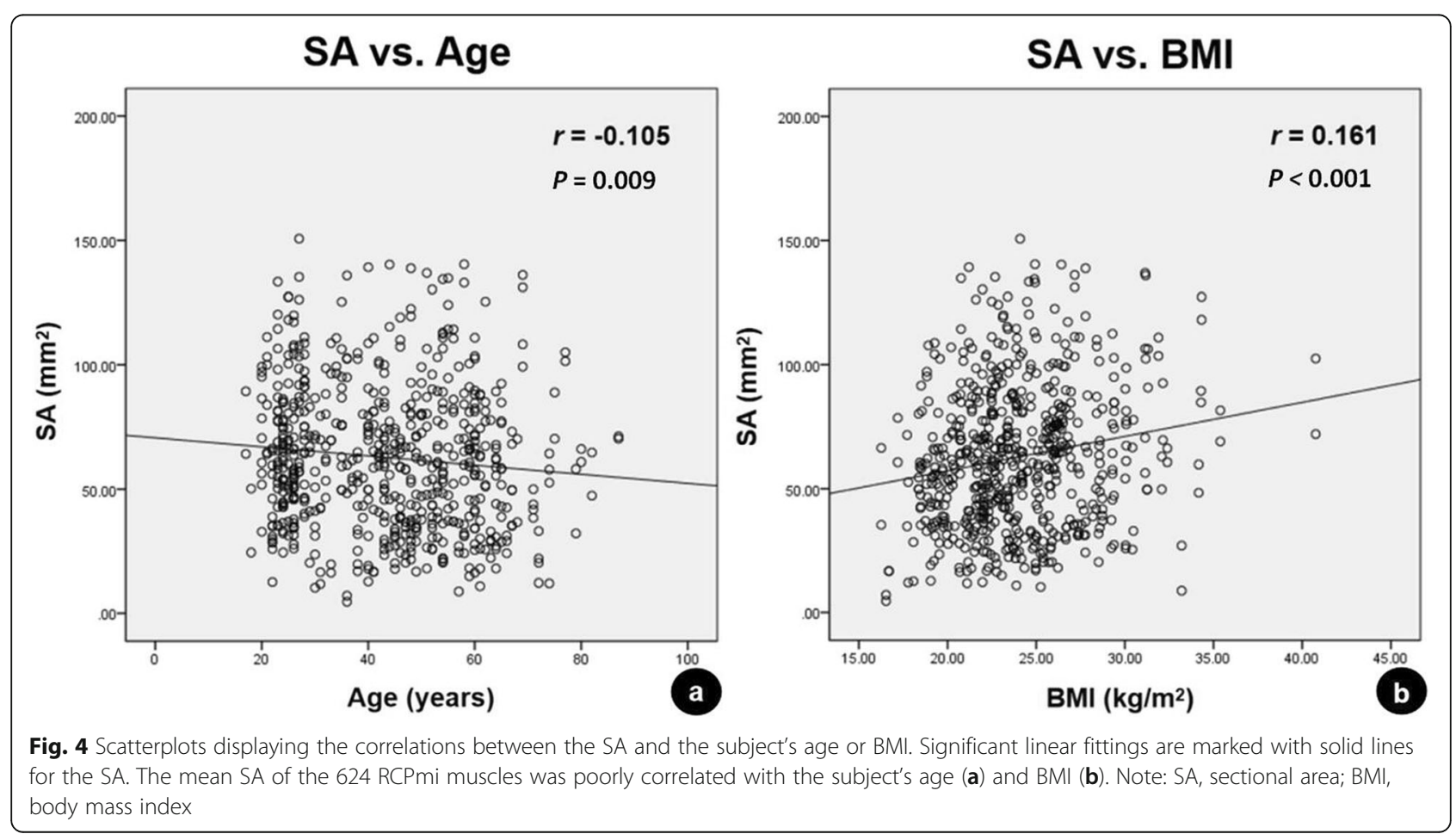


Table 2 The mean SA $\left(\mathrm{mm}^{2}\right)$ of the RCPmi muscle between different groups

\begin{tabular}{|c|c|c|c|c|c|c|}
\hline & \multicolumn{2}{|l|}{ Sides $(n, \%)$} & \multicolumn{2}{|l|}{ Gender $(n, \%)$} & \multicolumn{2}{|c|}{ RCPmi-TBNL attachment $(n, \%)$} \\
\hline & Left $(311,49.84)$ & Right $(313,50.16)$ & Male $(273,43.75)$ & Female $(351,56.25)$ & Positive $(123,19.71)$ & Negative $(501,80.29)$ \\
\hline SA & $61.79 \pm 28.76$ & $63.63 \pm 28.70$ & $75.54 \pm 29.17$ & $52.74 \pm 24.07$ & $55.95 \pm 26.76$ & $64.37 \pm 28.97$ \\
\hline$t$ & -0.799 & & 10.443 & & 2.932 & \\
\hline P & 0.424 & & $<0.001$ & & 0.003 & \\
\hline
\end{tabular}

All values are presented as mean \pm standard deviation

RCPmi muscle might be present in subjects with an RCPmi-TBNL attachment.

The RCPmi was the first deep suboccipital muscle found to be linked to the cervical spinal dura via the myodural bridge. However, its functional role through the MDB is still not fully elucidated [2]. Several reports have shown that changes in the SA of the RCPmi muscle are correlated with the severity of cervicocephalic pain syndrome, mTBI and headache syndrome [10-14]. Accordingly, it is crucial to accurately document the SA of the RCPmi to determine its influence. In the present study, the mean maximum SA of the 624 sampled RCPmi muscles was $62.71 \mathrm{~mm}^{2}$. There was a poor correlation with the subject's age, handedness, or BMI. In addition, a fair correlation was noticed between the SA and the body height in the whole group, and poor correlation in each male/female group. This suggested that gender was an important factor affecting SA of RCPmi muscles. Moreover, gender did account for some of the observed differences between the SA of the RCPmi muscle. The mean SA of the RCPmi muscle in males was significantly bigger than in females. These results were also corroborated by Yuan et al who found that the mean SA of the RCPmi muscle was gender-related [13]. In their study, they scanned subjects with $2 \mathrm{D} \mathrm{T}_{2^{-}}$ weighted MR imaging and used a measurement method similar to ours. Results of SA of the RCPmi were somewhat smaller in our study; however, the results of the study above were based on findings from $2 \mathrm{D} \mathrm{T}_{2^{-}}$ weighted images. The choice of MRI sequence and other scan parameters may also have contributed to this difference, thus making it difficult to quantitatively compare our results with previous studies. The present study is the first to measure the mean and variance of the maximum SA of the RCPmi muscle using 3D $\mathrm{T}_{2}$-weighted MR imaging. Knowing of the maximum SA of the RCPmi muscle is important for predicting the forces that it generates and then transmits to the spinal dura via the myodural bridge, which might be crucial for generating certain chronic pain and headache syndromes.

The RCPmi-TBNL attachment is composed of muscular bundles of the RCPmi joining with the TBNL. It has the appearance of a combination structure derived from these two critical myodural components, yet the physiology of this physical connection still remains unknown. Interestingly, the mean $\mathrm{SA}$ of the RCPmi in the positive RCPmi-TBNL attachment group was significantly smaller compared to the negative group, which has not been previously described. Furthermore, $19.71 \%$ of the RCPmi muscles were attached to the TBNL in the present study. It demonstrated that the physical RCPmiTBNL connection was more prevalent than it was observed by Yuan et al in 35 adult head-neck specimens [21]. This rather common variant in about $1 / 5$ subjects should be taken into account with the future measuring of the SA of the RCPmi muscle using MR imaging. It is

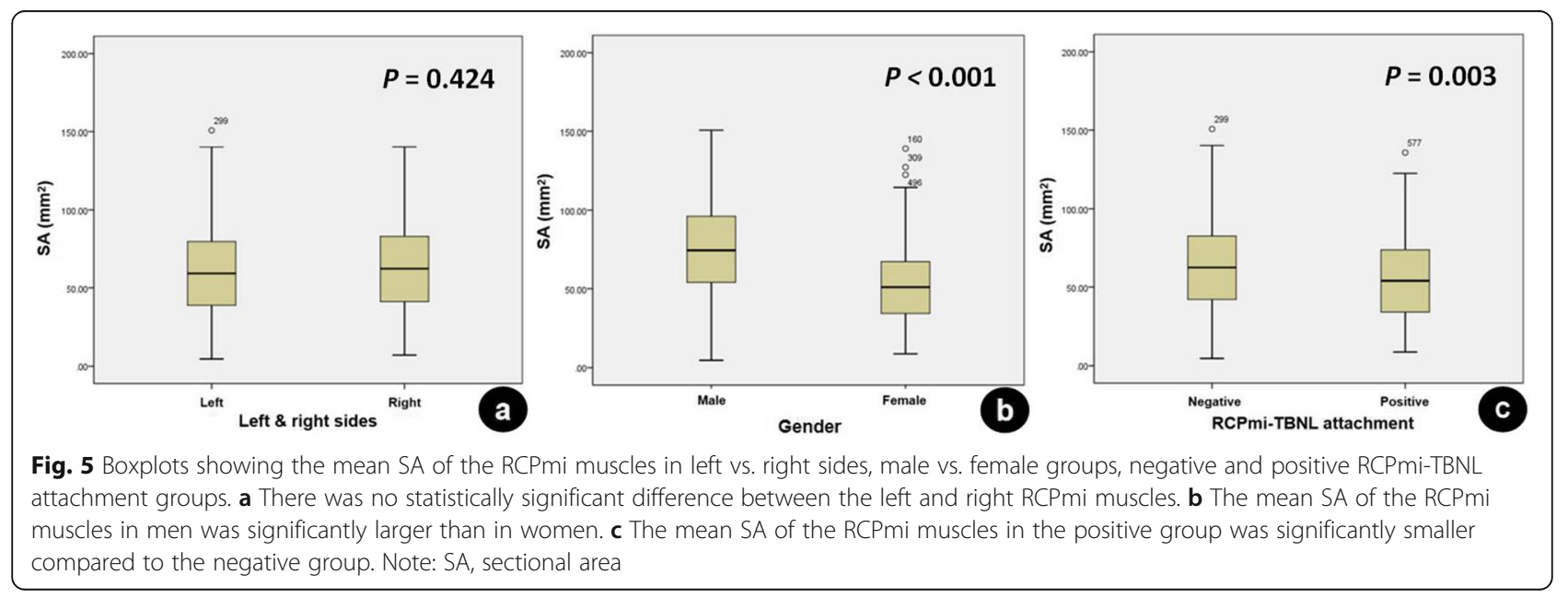


also essential to consider these differences in prospective studies looking at how the SA of the RCPmi muscles relate to head and neck pain syndromes. Both the RCPmi muscle and the TBNL are important components that connect to the dorsal cervical spinal dura via the MDB. The difference we observed in the SA of the RCPmi muscle with and without additional attachment to the TBNL may suggest a similar functional role for the RCPmi muscle and the TBNL. Assuming that the RCPmi and the TBNL are one complex structure, the existence of RCPmi-TBNL attachment would be reflected in a comparatively smaller SA of the RCPmi muscle. With more physical connections observed between myodural bridge and relevant musculature/ligament, we can get more evidence about the myodural bridge complex [24]. This may indicate that the RCPmi muscle and the TBNL work together as a MDB complex, which helps to understand better the potential role they have in the pathogenesis of cervicogenic pain syndromes [10-13]. Identifying the variations in the RCPmi muscle morphometry across a specific asymptomatic population provides the basis needed for future studies to assess the potential relationship of the SA to headache syndromes and chronic cervical pain.

The present study has few limitations. We did not account for other influential factors that might affect the SA of the RCPmi muscle, including the level of physical activity and workload. Yet, as the RCPmi muscle is small and its primary function does not involve carrying the load and producing large torques, it should not be affected by overall physical activity levels. The most common influential factors, including gender, age, left- or right-handed, left- or right-side, height and BMI, were assessed in this study, but further research should try to determine other possible factors, such as atlantooccipital distance. Furthermore, logistic regression and modeling should be applied in future studies. For those patients with anatomical variability in fibre/muscle orientation or even absence of the RCPmi muscle, a new assessment method may be required. Besides, further studies are needed to investigate the contribution of other components of the MDB, including the rectus capitis posterior major and the obliquus capitis inferior muscles, to the clinical manifestation of cervicogenic headaches. Future work concerning the function of the MDB should also be expanded to include data from other cervical deep extensor muscles attached to nuchal ligament.

\section{Conclusions}

The current study looked at the SA of the RCPmi muscle using $3 \mathrm{D} \mathrm{T}_{2}$-weighted $\mathrm{MR}$ imaging. Our results found a significantly smaller SA of the RCPmi in subjects with an RCPmi-TBNL attachment, suggesting a similar functional role for the RCPmi and the TBNL as part of the MDB. Besides, a larger SA of the RCPmi was correlated with the male gender. These findings suggest that the SA of the RCPmi ought to be interpreted with care for each patient since considerable variations might occur. The present study may serve as a baseline for further investigation of the RCPmi muscle and TBNL and their clinical significance in cervicogenic pain syndromes.

\section{Abbreviations \\ 2D: Two-dimensional; 3D: Three-dimensional; BMI: Body mass index; CSA: Cross-sectional area; CTTH: Chronic tension-type headache; MDB: Myodural bridge; MRI: Magnetic resonance imaging; mTBI: mild traumatic brain injury; NL: Nuchal ligament; PAA: Posterior atlantoaxial; PAO: Posterior atlanto-occipital; RCPmi: Rectus capitis posterior minor; SA: Sectional area; SDM: Spinal dura mater; TBNL: To be named ligament}

\section{Acknowledgments}

The authors thank all the participants. We would also like to thank Dr. Sahrish Qamar from the Chinese University of Hong Kong for proofreading the manuscript.

\section{Authors' contributions}

Study concepts: MYS, SBY, HJS; Study design: MYS, XH, MYW; Data acquisition: MYS, XH, MYW, DXN, BX; MR imaging acquisition: DXN, BX; Data analysis/interpretation: MYS, SBY, HJS; Statistical analysis: XH, MYW; Manuscript editing: MYS, LZX; Manuscript revision/review: MYS, LZX, SBY, HJS; Final approval of the version to be submitted: MYS, XH, MYW, DXN, BX, LZX, SBY, HJS. The author(s) read and approved the final manuscript.

\section{Funding \\ This work was supported by the National Natural Science Foundation of China (grant number 31571234 and 31871213).}

\section{Availability of data and materials}

The datasets used and/or analyzed during the current study are available from the corresponding author on reasonable request.

\section{Ethics approval and consent to participate}

The Ethics Committee of the First Affiliated Hospital of Dalian Medical University approved this retrospective study. Informed consent was waived due to the retrospective nature of this study.

Consent for publication

Not applicable.

\section{Competing interests}

The authors declare that they have no competing interests.

\section{Author details}

'Department of radiology, the first affiliated hospital of Dalian Medical University, Dalian, China. ${ }^{2}$ GE Healthcare, Beijing, China. ${ }^{3}$ Department of Anatomy, College of Basic Medicine, Dalian Medical University, Dalian 116044, People's Republic of China.

Received: 26 June 2019 Accepted: 10 February 2020

Published online: 14 February 2020

\section{References}

1. Hack GD, Koritzer RT, Robinson WL, Hallgren RC, Greenman PE. Anatomic relation between the rectus capitis posterior minor and the dura mater. Spine. 1995;20(23):2484-6. https://doi.org/10.1097/00007632-19951200000003.

2. Zumpano MP, Hartwell S, Jagos CS. Soft tissue connection between rectus capitis posterior minor and the posterior atlanto-occipital membrane: a cadaveric study. ClinAnat. 2006;9(6):522-7. https://doi.org/10.1002/ca.20220.

3. Humphreys BK, Kenin S, Hubbard BB, Cramer GD. Investigation of connective tissue attachments to the cervical spinal dura mater. Clin Anat. 2003;16(2):152-9. https://doi.org/10.1002/ca.10109. 
4. Scali F, Marsili ES, Pontell ME. Anatomical connection between the rectus capitis posterior major and the dura mater. Spine. 2011;36(25):E1612-4. https://doi.org/10.1097/brs.0b013e31821129df.

5. Mercer SR, Bogduk N. Clinical anatomy of ligamentum nuchae. ClinAnat. 2003;16(6):484-93. https://doi.org/10.1002/ca.10121.

6. PontellME SF, Enix DE, Battaglia PJ, Marshall E. Histological examination of the human obliquus capitis inferior myodural bridge. Ann Anat. 2013;95(6): 522-6. https://doi.org/10.1016/j.aanat.2013.04.013.

7. Liu P, Li C, Zheng N, Xu Q, Yu SB, Sui HJ. The myodural bridge existing in the Nephocaenaphocaenoides. PLoS One. 2017;12(3):e0173630. https://doi. org/10.1371/journal.pone.0173630.

8. Zheng N, Yuan XY, Chi YY, et al. The universal existence of myodural bridge in mammals: an indication of a necessary function. Sci Rep. 2017;7(1):8248. https://doi.org/10.1038/s41598-017-06863-z.

9. Zheng $\mathrm{N}$, Chi YY, Yang XH, et al. Orientation and property of fibers of the myodural bridge in humans. Spine J. 2018;18(6):1081-7. https://doi.org/10. 1016/j.spinee.2018.02.006

10. Fernández-de-Las-Peñas C, Bueno A, Ferrando J, Elliott JM, Cuadrado ML, Pareja JA. Magnetic resonance imaging study of the morphometry of cervical extensor muscles in chronic tension-type headache. Cephalalgia. 2007;27(4):355-62. https://doi.org/10.1111/j.1468-2982.2007.01293.x.

11. Fernández-de-Las-Peñas C, Cuadrado ML, Arendt-Nielsen L, Ge HY, Pareja JA. Association of cross-sectional area of the rectus capitis posterior minor muscle with active trigger points in chronic tension-type headache: a pilot study. Am J Phys Med Rehabil. 2008;87(3):197-203. https://doi.org/10.1097/ phm.0b013e3181619766.

12. Uthaikhup S, Assapun J, Kothan S, Watcharasaksilp K, Elliott JM. Structural changes of the cervical muscles in elder women with cervicogenic headache. MusculoskeletSciPract. 2017;29:1-6. https://doi.org/10.1016/j.msksp.2017.02.002.

13. Yuan XY, Yu SB, Liu C, et al. Correlation between chronic headaches and the rectus capitis posterior minor muscle: a comparative analysis of crosssectional trail. Cephalalgia. 2017;37(11):1051-6. https://doi.org/10.1177/ 0333102416664775.

14. Xu Q, Yu SB, Zheng N, et al. Head movement, an important contributor to human cerebrospinal fluid circulation. Sci Rep. 2016;6:31787. https://doi.org/ 10.1038/srep31787.

15. Lieber RL, Friden J. Functional and clinical significance of skeletal muscle architecture. Muscle Nerve. 2000;23:1647-66. https://doi.org/10.1002/10974598(200011)23:11<1647::aid-mus1>3.3.co;2-d.

16. Fakhran S, Qu C, Alhilali LM. Effect of the suboccipital musculature on symptom severity and recovery after mild traumatic brain injury. AJNR Am J Neuroradiol. 2016;37(8):1556-60. https://doi.org/10.3174/ajnr.a4730.

17. Okada E, Matsumoto M, Ichihara D, et al. Cross-sectional area of posterior extensor muscles of the cervical spine in asymptomatic subjects: a 10-year longitudinal magnetic resonance imaging study. Eur Spine. 2011;/20(9): 1567-73. https://doi.org/10.1007/s00586-011-1774-x.

18. Dawson RM, Latif Z, Haacke EM, Cavanaugh JM. Magnetic resonance imaging-based relationships between neck muscle cross-sectional area and neck circumference for adults and children. Eur Spine. 2013;J22(2):446-52. https://doi.org/10.1007/s00586-012-2482-x.

19. Dean NA, Mitchell BS. Anatomic relation between the nuchal ligament (ligamentum nuchae) and the spinal dura mater in the craniocervical region. Clin Anat. 2002;15(3):182-5. https://doi.org/10.1002/ca.10001.

20. Zheng $N$, Yuan XY, Li YF, et al. Definition of the to be named ligament and vertebrodural ligament and their possible effects on the circulation of CSF. PLoS One. 2014;9(8):e103451. https://doi.org/10.1371/journal.pone.0103451.

21. Yuan XY, Li C, Sui JY, et al. The second terminations of the suboccipital muscles: an assistant pivot for the to be named ligament. PLoS One. 2017; 12(5):e0177120. https://doi.org/10.1371/journal.pone.0177120.

22. Koo TK, Li MY. A guideline of selecting and reporting Intraclass correlation coefficients for reliability research. J Chiropr Med. 2017;15(2):155-63. https:/ doi.org/10.1016/j.jcm.2016.02.012.

23. Akoglu H. User's guide to correlation coefficients. Turk J Emerg Med. 2018; 18(3):91-3. https://doi.org/10.1016/j.tjem.2018.08.001.

24. Zheng N, Chung BS, Li YL, et al. The myodural bridge complex defined as a new functional structure. Surg Radiol Anat. 2019. https://doi.org/10.1007/ s00276-019-02340-6

\section{Publisher's Note}

Springer Nature remains neutral with regard to jurisdictional claims in published maps and institutional affiliations.

\section{Ready to submit your research? Choose BMC and benefit from:}

- fast, convenient online submission

- thorough peer review by experienced researchers in your field

- rapid publication on acceptance

- support for research data, including large and complex data types

- gold Open Access which fosters wider collaboration and increased citations

- maximum visibility for your research: over $100 \mathrm{M}$ website views per year

At BMC, research is always in progress.

Learn more biomedcentral.com/submissions 